\title{
ESTUDO DE CASO DO PROCESSO DE EXTRAÇÃO DO ÓLEO ESSENCIAL DA MADEIRA DE CANDEIA NO SUL DE MINAS GERAIS
}

\author{
Paulo Roberto Longhi ${ }^{1}$, Alexandre Jorge Duarte de Souza ${ }^{2}$, Ronaldo Francisco Garcia ${ }^{3}$, \\ Vladmir Rodrigues Piovezan ${ }^{4}$ \\ ${ }^{1}$ Administrador de Empresas, M.Sc., UNESP, Itapeva, SP, Brasil - prlonghi@ itapeva.unesp.br \\ ${ }^{2}$ Eng. de Produção Mecânica, M.Sc., Doutorando em Eng. de Materiais, UNESP, Itapeva, SP, Brasil - alexandre@ @itapeva.unesp.br \\ ${ }^{3}$ Eng. Químico, Itapeva, SP, Brasil \\ ${ }^{4}$ Administrador de Empresas, M.Sc., Itapeva, SP, Brasil - vlady38@bol.com.br \\ Recebido para publicação: 27/09/2007 - Aceito para publicação: 08/10/2008
}

\begin{abstract}
Resumo
Este artigo apresenta um estudo de caso sobre os processos que estão sendo desenvolvidos e implementados para o cultivo e uso da madeira de candeia (Eremanthus erythropappus) nativa do sul de Minas Gerais, que agora vem sendo explorada através de técnicas de manejo sustentável, e sobre os respectivos processos de corte, carregamento, transporte e beneficiamento, com a finalidade da obtenção do óleo essencial de candeia. Por último mostra que o processo pode ser considerado de baixo impacto ambiental devido à associação das técnicas de manejo, uso de mão-de-obra local e da utilização dos resíduos gerados como fonte de energia.

Palavras-chave: Madeira de candeia; cultivo de candeia; óleo essencial de candeia; extração de óleo essencial; óleo alfabisabolol.
\end{abstract}

\begin{abstract}
Case-study of the essential oil extraction process from Eremanthus erythropappus pappers wood in the south of Minas Gerais - Brazil. Presents a case-study on the process and methods developed for use and cultivation of "Candeia" (Eremanthus erythropappus) in a sustainable way. Also shows the extraction process to obtain essential "Candeia" Oil in several steps: sawing, loading, transportation and manufacturing. And finally consider the process with a low environmental impact, due to an association of sustainable management cultivation systems, local labors and waste used as an energy source.

Keywords: Candeia wood; candeia cultivation; essential oil; extraction of essential oil; alphabisabolol oil.
\end{abstract}

\section{INTRODUÇÃO}

O objetivo deste artigo é apresentar um estudo de caso sobre os processos que estão sendo desenvolvidos e implementados para o cultivo e uso da madeira de candeia (Eremanthus erythropappus) através de técnicas de manejo sustentável no sul de Minas Gerais.

A candeia é uma planta da família Asteraceae e pertence ao grupo ecológico das ecótonas, sendo considerada precursora na invasão de campos. Ela se desenvolve rapidamente em campos abertos, formando povoamentos mais ou menos puros. Existem várias espécies de candeia, porém a Eremanthus erythropappus (DC. Macleish) é economicamente a de maior ocorrência em Minas Gerais.

A espécie Eremanthus erythropappus se desenvolve em sítios com solos pouco férteis, rasos e predominantemente em áreas de campos de altitude, entre 900 e $1.700 \mathrm{~m}$. É uma espécie de múltiplos usos, porém sua madeira é mais utilizada como moirão de cerca, pela sua durabilidade, e para a produção de óleo essencial, cujo principal componente, o alfabisabolol, possui propriedades antiflogísticas, antibacterianas, antimicóticas, dermatológicas e espasmódicas. 
Os produtos obtidos da candeia alcançam preços relativamente altos no mercado. Atualmente, os produtores rurais pagam entre US\$16,00 e US\$25,00 pela dúzia de moirões. Já as indústrias que extraem o óleo essencial pagam em média entre US\$23,00 e US\$ 41,00 pelo metro estéreo de madeira. O óleo essencial de candeia natural bruto e o alfabisabolol são comercializados nos mercados nacional e internacional, podendo alcançar entre US\$27,00 e US\$ 60,00 por quilo, respectivamente.

No Brasil existem cinco indústrias de óleo essencial de candeia natural bruto, com uma produção anual estimada em cerca de 170 mil quilos, sendo grande parte exportada, principalmente para países europeus. Já o alfabisabolol, obtido a partir da destilação do óleo essencial de candeia bruto, é produzido apenas por três indústrias brasileiras, que o vendem para distribuidores e indústrias de cosméticos e de fármacos, como componente em formulações para cosméticos, protetores solares, cremes dentais, loções pós-barba, cremes para barbear e produtos para depilação, entre outros.

A regulamentação da extração dessa madeira consta na Portaria $n^{\circ} 184$ do Instituto Estadual de Floresta (IEF), de 10 de dezembro de 2004. Essa portaria dispõe sobre normas para elaboração de Plano de Manejo para Produção Sustentada de Candeia Eremanthus erythropappus no estado de Minas Gerais, sob a supervisão do Departamento de Ciências Florestais da Universidade Federal de Lavras (UFLA) MG.

A candeia é representada por várias espécies, a saber: Eremanthus arboreus (Gardner) MacLeish, Eremanthus brasiliensis (Gardner) MacLeish, Eremanthus polycephalus (DC.) MacLeish, Eremanthus glomerulatus Less., Eremanthus erythropappus (DC.) MacLeish (Figura 1) e Eremanthus incanus (Less.) Less., entre outras. A espécie utilizada neste estudo é Eremanthus erythropappus.

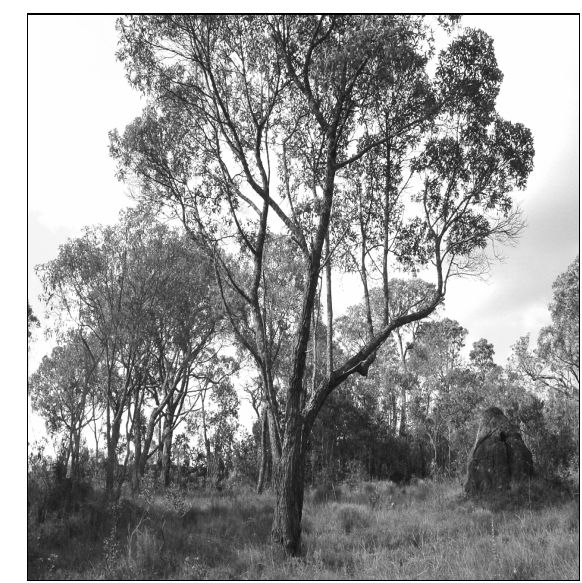

Figura 1. Árvore de candeia da espécie Eremanthus erythropappus.

Figure 1. Candeia tree from the specie Eremanthus erythropappus.

A candeia (Eremanthus erythropappus) é classificada como da família Asteraceae, pertence ao grupo ecológico das ecótonas e é considerada precursora na invasão de campos (CARVALHO, 1994).

Essa espécie se desenvolve rapidamente em campos abertos, formando povoamentos mais ou menos puros. Isso também acontece no interior da floresta quando há alguma perturbação, pois é uma espécie heliófila, sendo beneficiada pela entrada de luz. É uma árvore cuja altura varia de 2 a $10 \mathrm{~m}$, podendo seu diâmetro atingir até $35 \mathrm{~cm}$.

O tronco dessa árvore possui uma casca grossa e cheia de fendas no fuste. Nos galhos mais novos, a casca torna-se menos rústica. As folhas têm uma característica marcante, que é a dupla coloração. Na parte superior são verdes e glabras e na parte inferior possuem um tom branco, tomentoso, e são aveludadas (CORRÊA, 1931). As folhas são simples, opostas com pilosidade cinérea (CHAVES; RAMALHO, 1996). As flores são hermafroditas e se apresentam em inflorescências de cor púrpura nas extremidades dos ramos (ARAÚJO, 1944). As características das folhas e da inflorescência facilitam a identificação da espécie mesmo à distância.

Conforme CETEC (1994), na Estação Ecológica do Tripuí, em Ouro Preto (MG), no ano de 1993 a candeia começou a desenvolver seus botões florais em março. As flores abriram de maio a agosto 
e o pico de floração ocorreu no mês de julho, quando alguns indivíduos já começaram a frutificar, apresentando o pico entre os meses de setembro e outubro, quando se inicia a dispersão de sementes ou aquênios.

O fruto é do tipo aquênio, com superfície cilíndrica e com dez arestas, de cor pardo-escura, com aproximadamente $2 \mathrm{~mm}$ de comprimento. Cada fruto contém uma só semente.

Uma característica interessante dessa espécie é seu desenvolvimento em sítios com solos pouco férteis, rasos e predominantemente em áreas de campos de altitude, com esta variando entre $1.000 \mathrm{e}$ $1.700 \mathrm{~m}$. Enfim, a candeia se desenvolve em locais em que seria difícil a implantação de culturas agrícolas ou mesmo a implantação de alguma outra espécie florestal.

A madeira é branca ou acinzentada, com grã mais escura, e seu peso específico é de $0,912 \mathrm{~g} / \mathrm{cm}^{3}$. Apresenta resistência ao esmagamento, carga perpendicular de $339 \mathrm{~kg} / \mathrm{cm}^{2}$ e carga paralela de $472 \mathrm{~kg} / \mathrm{cm}^{2}$ (CORRÊA, 1931). É uma espécie florestal de múltiplos usos, sendo utilizada como moirão de cerca pela sua durabilidade, e oferece também um óleo essencial cujo princípio ativo é o alfabisabolol, que exibe propriedades antiflogísticas, antibacterianas, antimicóticas, dermatológicas e espasmódicas (TEIXEIRA et al., 1996). Por causa dessas propriedades, o alfabisabolol é utilizado na fabricação de medicamentos e cosméticos.

Na sequência será apresentada uma revisão bibliográfica referente ao processo de silvicultura da candeia no sul de Minas Gerais, seguida da descrição do estudo de caso.

\section{Áreas de ocorrência}

Segundo Carvalho (1994), a candeia ocorre na América do Sul, sendo encontrada no nordeste da Argentina, no norte e leste do Paraguai e no Brasil. Pedralli, Teixeira e Nunes (1996) indicam que se pode encontrar a candeia, no Brasil, nos estados de Minas Gerais, Bahia, Espírito Santo e Rio de Janeiro. Carvalho (1994) cita outros estados nos quais a candeia também pode ser encontrada, como Goiás, Paraná, Rio Grande do Sul, Santa Catarina, São Paulo e Distrito Federal.

Em Minas Gerais, a área de ocorrência da candeia vem ilustrada na figura 2. Nessa mesma figura é mostrada a área de execução do Projeto Candeia.

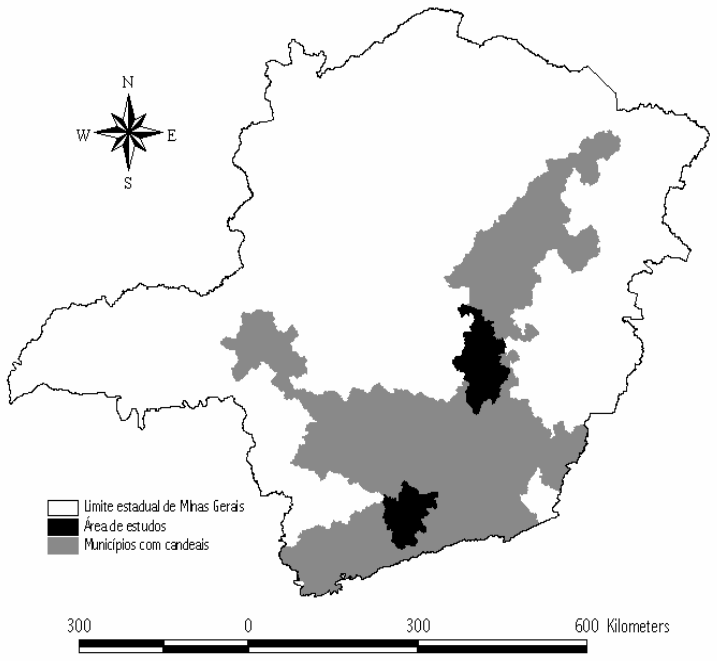

Figura 2. Área de ocorrência e de estudo da candeia em Minas Gerais.

Figure 2. Candeia occurrence areas in the State of Minas Gerais.

\section{Caracterizações do ambiente onde se encontra a candeia}

O clima, segundo a classificação de Köppen, é mesotérmico úmido do tipo Cwb, tropical de altitude, com verões suaves. A temperatura do mês mais quente, dependendo da altitude do local considerado, varia de $22{ }^{\circ} \mathrm{C}$ a $30^{\circ} \mathrm{C}$, a temperatura média anual varia entre 18 e $20^{\circ} \mathrm{C}$, e a média anual de 
precipitação pluviométrica está entre 1.400 e $1.550 \mathrm{~mm}$. Os meses mais chuvosos correspondem a novembro, dezembro, janeiro e fevereiro, e as menores precipitações ocorrem em junho, julho e agosto.

Nos campos de altitude da região sul de Minas, o material de origem é denominado BI, gnaisses, migmatitos, granitoides gnaisses e xistos grafitosos, ultramáficas e máficas, formações ferríferas, conditos e quartzitos. O solo é classificado como Cambissolo álico $(\mathrm{Ca})$ e Cambissolo distrófico $(\mathrm{Cd})$.

Já em áreas com altitude em torno de 1000 m, no sul de Minas, o material de origem é AX, micaxisto, quartzito anfebolitos, cálcio-cilicáticas e gnaisses. O solo é classificado como Cambissolo álico $(\mathrm{Ca})$, ocorrendo também Latossolo Vermelho Escuro distrófico (LEd) e Latossolo Vermelho Amarelo distrófico (LVd).

De maneira geral, a fertilidade e textura do solo, onde ainda se encontram remanescentes de candeia, tem como características médias:

a) $\mathrm{O}$ pH é baixo, com valor médio de 5,1 e desvio padrão 0,3 .

b) A matéria orgânica pode ser classificada como valores bons, com média de 2,2 dag/kg e desvio padrão 0,9 .

c) O cálcio apresenta valor de médio a baixo ou $0,3 \mathrm{mg} / \mathrm{dm}^{3}$ e desvio padrão 0,2 .

d) O magnésio apresenta valores de baixo a muito baixo ou $0,1 \mathrm{cmolc} / \mathrm{dm}^{3}$.

e) O potássio apresenta grande variabilidade em sua disponibilidade nas áreas com valores de bons a baixo, na grandeza de $40,7 \mathrm{mg} / \mathrm{dm}^{3}$ e desvio padrão 21,7 .

f) O fósforo apresenta baixos valores de $1,4 \mathrm{mg} / \mathrm{dm}^{3}$ e desvio padrão 0,4 .

g) O alumínio apresenta valores médios de $1,2 \mathrm{cmolc} / \mathrm{dm}^{3}$ e desvio padrão de 0,5 . O índice de saturação de bases é em média de $9,7 \%$.

h) O índice de saturação de alumínio é de $67,6 \%$.

i) A soma de bases trocáveis é de $0,5 \mathrm{cmolc} / \mathrm{dm}^{3}$ com desvio padrão 0,2 .

j) A capacidade de troca catiônica efetiva é em média de $1,7 \mathrm{cmolc} / \mathrm{dm}^{3}$ com desvio de 0,6 , e a capacidade de troca catiônica a pH 7,0 é de $6,6 \mathrm{cmolc} / \mathrm{dm}^{3} \mathrm{com}$ desvio padrão de 2,8 .

Com base nos valores de $\mathrm{pH}$, alumínio, acidez potencial e saturação por alumínio, verifica-se que o solo no qual a candeia se encontra possui acidez elevada, o que pode influenciar negativamente no desenvolvimento do sistema radicular e na disponibilidade de macronutrientes. A soma de bases apresenta baixos valores, evidenciando a baixa fertilidade desse solo.

Com relação às características físicas do solo, as distribuições granulométricas por tamanho indicam solos variando de textura média a arenosa, com $68,7 \%$ de areia, 20,8\% de argila e 11,2\% de silte, em média.

\section{Sistema silvicultural}

Os sistemas silviculturais são um conjunto de intervenções do homem na floresta, tais como desbastes de árvores, remoção e substituição por novas culturas, de modo a aumentar sua produtividade. Um sistema silvicultural é caracterizado pelo método de regeneração utilizado e pelo arranjo no espaço da cultura em questão, de modo a facilitar sua proteção e colheita.

Para que a prática de manejo florestal sustentado tenha êxito, é necessário o conhecimento teórico desses sistemas.

Especificamente, a candeia, para fins comerciais, deve ser restrita a áreas homogêneas com a espécie ou nas bordas das matas. O conjunto de métodos silviculturais que mais se aproxima ao manejo desejável para essa espécie é o que se baseia no método de transformação por via da sucessão dirigida.

A seguir, será apresentada uma síntese de alguns métodos que compõem o espectro dos métodos de transformação por via da sucessão dirigida.

Sistemas de corte raso com regeneração natural

Em certas condições, o sistema de corte raso pode ser seguido por uma regeneração natural bem sucedida, que pode ser obtida por meio do banco de sementes ou mudas já existentes na área, ou por meio da dispersão das sementes das árvores adjacentes e/ou circunvizinhas, através do vento, água ou por animais silvestres.

Ao optar por esse sistema, a derrubada (corte raso) deverá ser feita após a dispersão das sementes $\mathrm{da}(\mathrm{s})$ espécie(s) de interesse, para haver redução dos danos à regeneração causados pela exploração (quebra das mudas). 
Sistemas de porta-sementes com regeneração natural

Para espécies pioneiras, que é uma das características da candeia, pode-se adotar esse sistema, se a regeneração natural for intensa. Para isso é necessário ter grande dispersão de sementes (chuva de sementes), normalmente pelo vento, a partir de árvores porta-sementes. No caso da candeia, a dispersão ocorre nos meses de agosto a outubro.

$\mathrm{O}$ sucesso para que haja uma alta intensidade de regeneração natural para a candeia é que as sementes, estando em contato com o solo, recebam luminosidade direta e água da chuva. A candeia não apresenta problemas de dormência e, portanto, o solo deve estar limpo, para que a regeneração seja intensa.

A aplicação desse sistema (Figura 3) é simples e a cobertura vegetal do solo é restabelecida com rapidez e de forma segura, visto que as novas mudas estão mais aptas morfologicamente às condições do sítio (fatores bióticos e abióticos). Outra característica importante deste sistema é a redução (quase zero) das despesas necessárias com a implantação da regeneração.

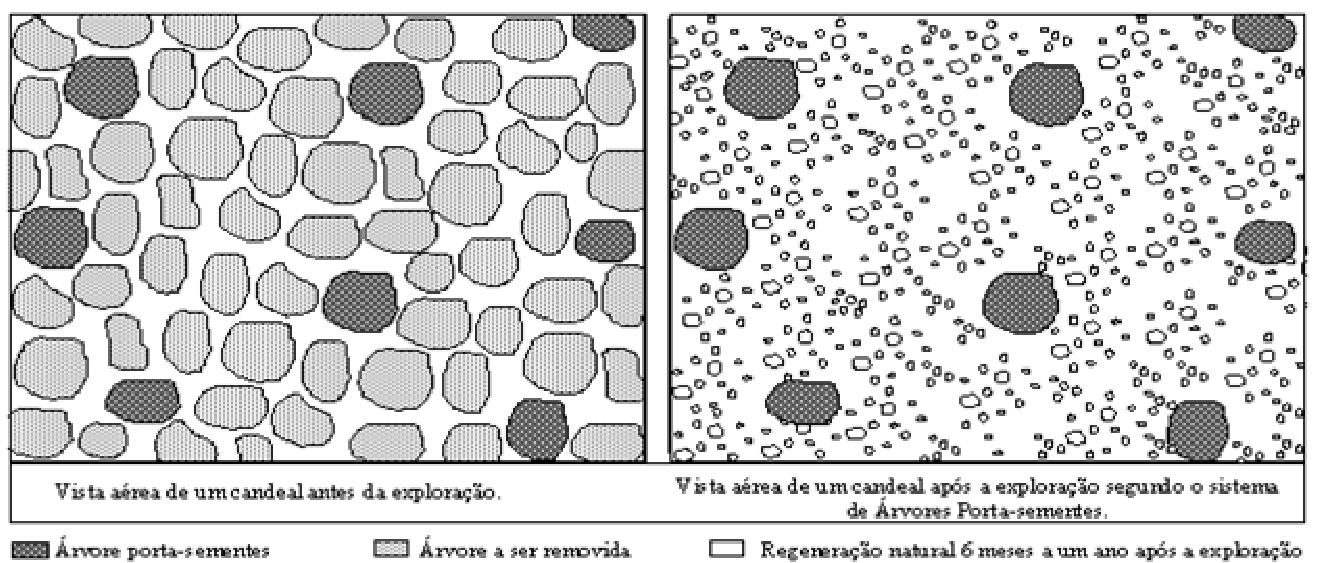

Figura 3. Sistema de porta-semente.

Figure 3. Seed tree system.

Sistemas de seleção de grupo ou sistema de corte seletivo em grupo

O sistema de corte seletivo em grupo (Figura 4), aplicado em espécies que sejam exigentes de luz, baseia-se na remoção de um pequeno grupo de árvores na operação de exploração e derrubada. Dessa forma, pequenas clareiras são formadas para que haja boa incidência de luz solar e esta seja distribuída por toda a área. O propósito é garantir que a regeneração natural das espécies de interesse ocorra de forma satisfatória.

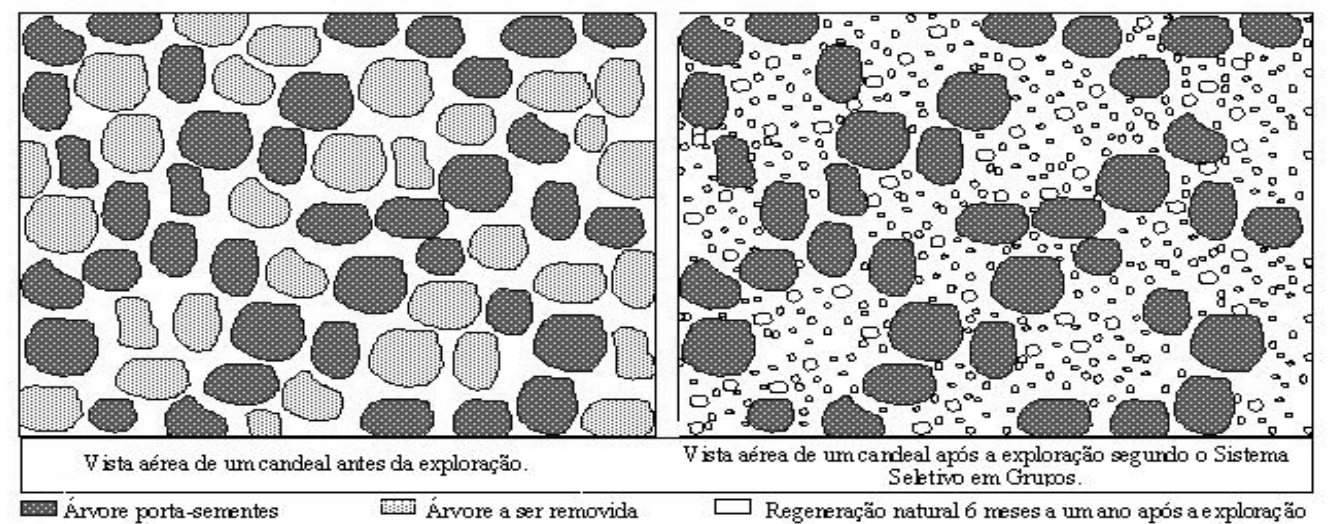

Figura 4. Sistema de seleção em grupo.

Figure 4. Group selection system. 
Sistemas em faixa

O sistema em faixa (Figura 5) difere em poucos detalhes dos outros sistemas, tendo em comum a característica de deixar o estrato superior visando proteger naturalmente o solo. Nesse caso, a regeneração dirigida é conduzida em estreitas faixas abertas na floresta.

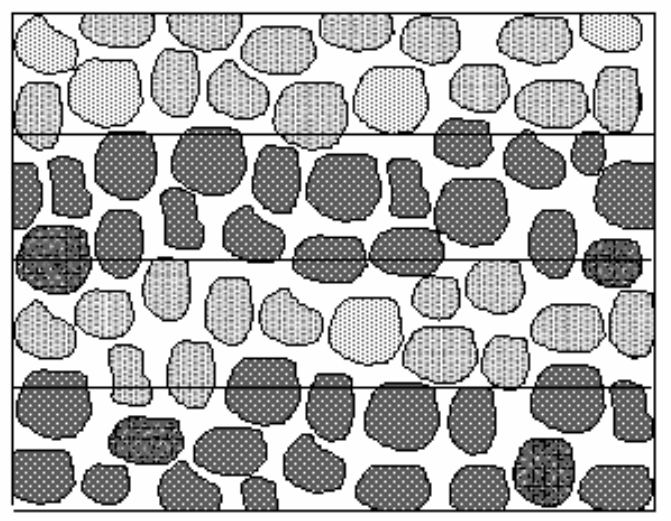

Vista aérea de um candeal antes da exploração

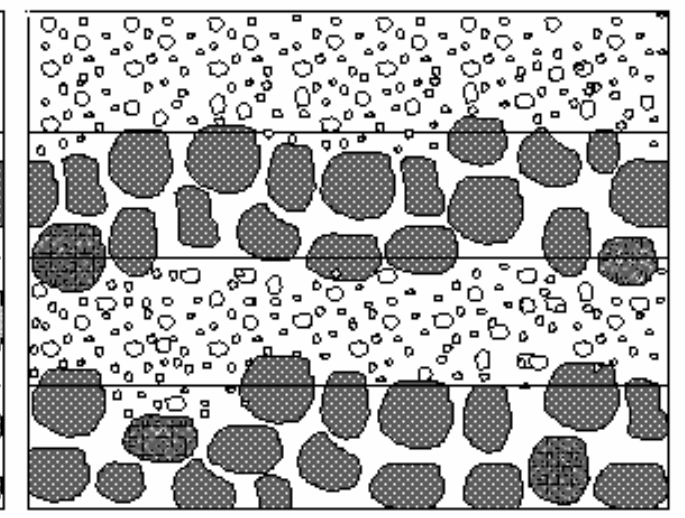

Vis ta aérea de um candeal após a exploração, segundo o Sis tema em Faixas

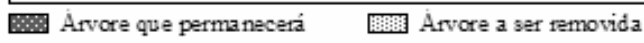

Regeneração natural 6 meses a um ano após a exploração

Figura 5. Sistema em faixas.

Figure 5. Strep system.

Sistema de cobertura em faixas

Esse sistema foi desenvolvido a partir do sistema uniforme de floresta de cobertura, com algumas modificações. Os cortes de condução da regeneração são realizados seguindo a direção predominante dos ventos, evitando assim maiores danos.

O sistema de floresta de cobertura em faixa requer poucas alterações para se converter em um sistema de cortes sucessivos de regeneração (corte de semeadura, corte secundário e corte final). $\mathrm{O}$ resultado final desse sistema consiste na abertura de estreitas faixas dos estratos superiores, com o objetivo de proporcionar um maior ou menor ângulo de infiltração de luz à regeneração, seguindo a direção predominante dos ventos na região.

Assim que a regeneração de interesse estiver suficientemente estabelecida na faixa, um segundo corte de semeadura é feito ao longo da segunda faixa adjacente à primeira, seguindo a direção do vento. Quando a regeneração estiver suficientemente estabelecida na segunda faixa, esta será submetida ao corte secundário, e a primeira faixa, aos sucessivos cortes de condução (desbaste, melhoramento, refinamento e colheita). Na terceira faixa, adjacente à segunda, é feito então o corte de semeadura. Esses tratamentos para favorecimento da regeneração são conduzidos progressivamente seguindo a direção dos ventos predominantes em uma série de estreitas faixas adjacentes às anteriores e distribuídas regularmente sobre toda a floresta a ser manejada.

As vantagens do sistema de floresta de cobertura em faixa são: proporciona uma melhor proteção da floresta contra a ação dos ventos, favorece a regeneração das espécies exigentes de luz, minimiza os danos ao povoamento durante as operações de corte e extração, melhora o controle do progresso da regeneração e proporciona uma melhor aparência à floresta devido à diversidade de estratos. Como desvantagem, pode-se citar: as atividades silviculturais não são concentradas em uma única área, o que aumenta ainda mais os custos de condução do povoamento, e o sistema demanda um rigoroso e específico mapeamento da área e faixas de regeneração.

Esse método, segundo Matthews (1994), foi utilizado a mais ou menos 150 anos em povoamentos puros de abeto vermelho na Noruega, com adição de espécies exigentes de luz e tolerantes à sombra.

A partir da $2^{\text {a }}$ Guerra, vem sendo praticado no sudeste da Alemanha, com algumas adaptações para favorecer as espécies locais. 
Sistema de faixas em grupo

Esse sistema é uma modificação do sistema de floresta de cobertura em faixa. De modo geral, o planejamento com relação à abertura do dossel e as faixas são iguais, somente o modo de como esses cortes são executados é que difere.

No primeiro caso, o corte de semeadura consiste de uma abertura total do dossel, dispostos em faixas espaçadas regularmente sobre toda a área. Já para o segundo caso, a abertura do dossel superior também é feita em faixas, porém não é removida toda a cobertura florestal da faixa. A intenção é favorecer grupos de espécies de interesse e com crescimento superior. São abertas pequenas clareiras, com diâmetros médios variando entre 30-50 m, dependendo do sítio e das características ecológicas da(s) espécie(s) envolvida(s). Essas clareiras, destinadas a favorecer o desenvolvimento dos grupos de espécies de interesse, são ampliadas continuamente com o passar dos anos.

O progresso dos cortes (de regeneração, secundário e colheita) e a forma das faixas são pouco regulares nesse sistema, quando comparadas com o sistema de floresta de cobertura em faixa. As vantagens desse método são: a regeneração pode ser estabelecida de maneira mais simples e rápida, por favorecer grupos de indivíduos com melhor desenvolvimento, a formação de estratos de diferentes idades e tamanho proporcionam uma melhor proteção aos estágios mais jovens, os povoamentos mistos podem ser facilmente conduzidos e a aparência da floresta torna-se mais atraente à fauna. A maior desvantagem está nos danos causados ao estoque de regeneração das espécies de interesse, durante a exploração. Esses danos tornam-se maiores quando a área possui uma inclinação elevada. Esse sistema foi amplamente utilizado por H. von Huber, do serviço florestal alemão, especificamente na Bavária e em toda a Europa Central.O corte da madeira é realizado sempre da parte mais baixa do terreno para a parte mais alta, de modo que as árvores cortadas caem sobre uma área já limpa (cortada).

\section{Descrição do processo de extração do óleo essencial da madeira - Estudo de Caso}

A seguir serão apresentadas passo a passo as etapas pós-colheita para o processo de extração do óleo essencial. Ressalte-se que o sistema silvicultural utilizado é o sistema de porta-sementes com regeneração natural.

Separação por lote de colheita

A madeira colhida no campo ou no manejo sustentado é colocada no pátio da empresa, separada em montes (lotes identificados para facilitar a rastreabilidade e atendendo a uma exigência da norma ISO9002), conforme figuras 6 e 7.

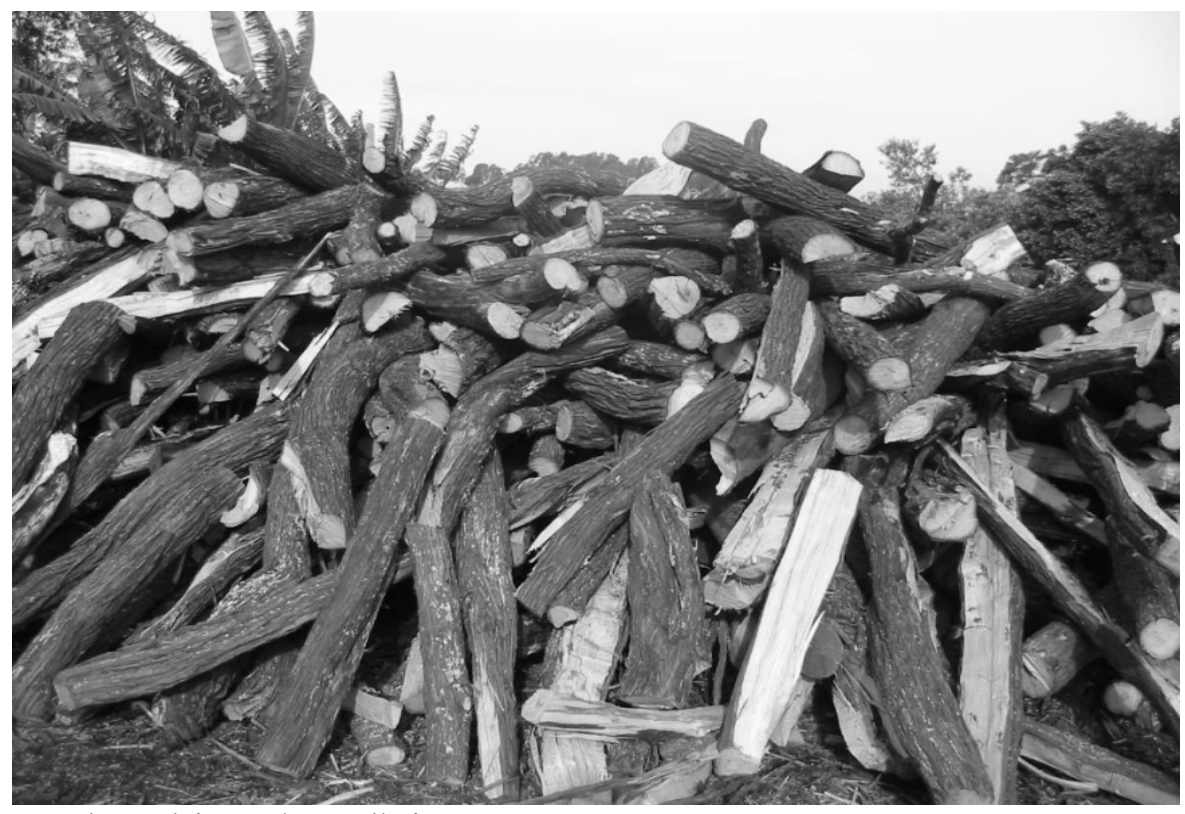

Figura 6. Lote de madeira após a colheita.

Figure 6. Wood batches after harvest. 


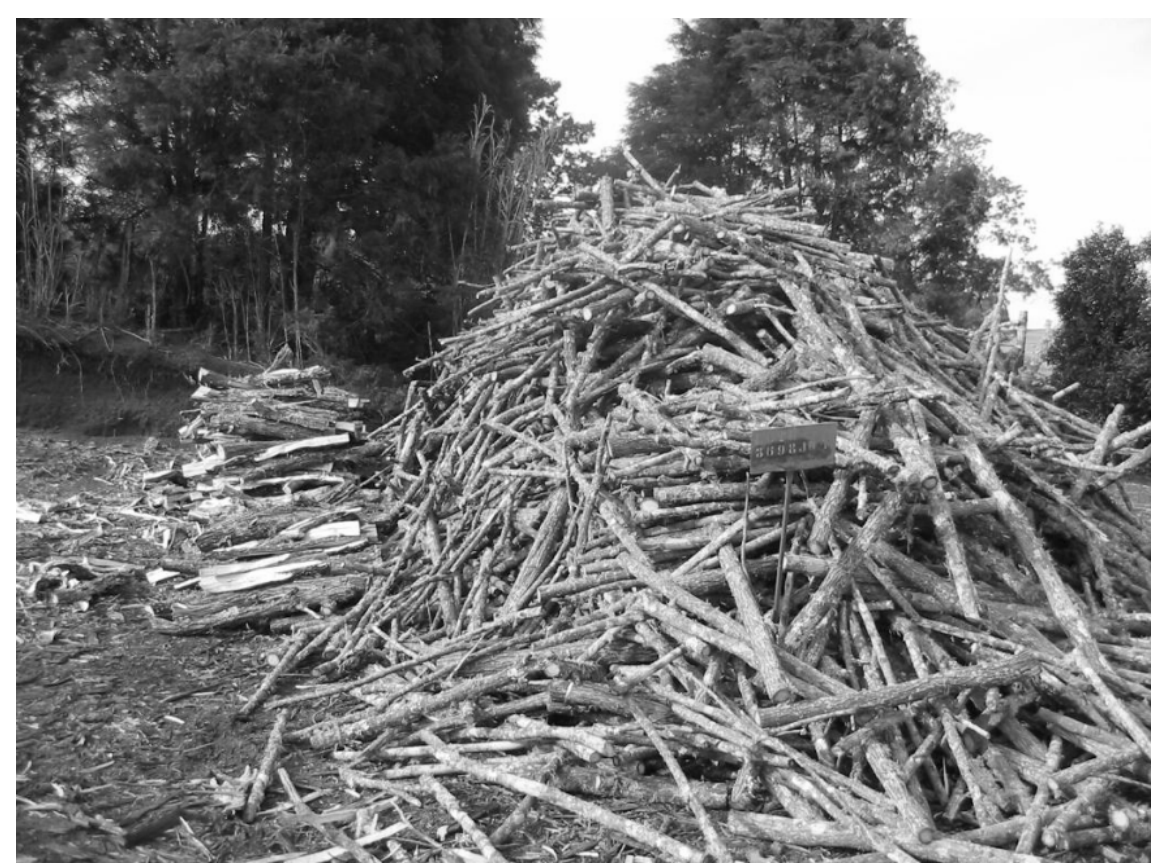

Figura 7. Lote de madeira após a colheita.

Figure 7. Wood batches after harvest.

Seccionamento de toras

A madeira com diâmetro acima de $30 \mathrm{~cm}$ passa pelo rachador, para facilitar sua passagem na garganta do picador (Figura 8).

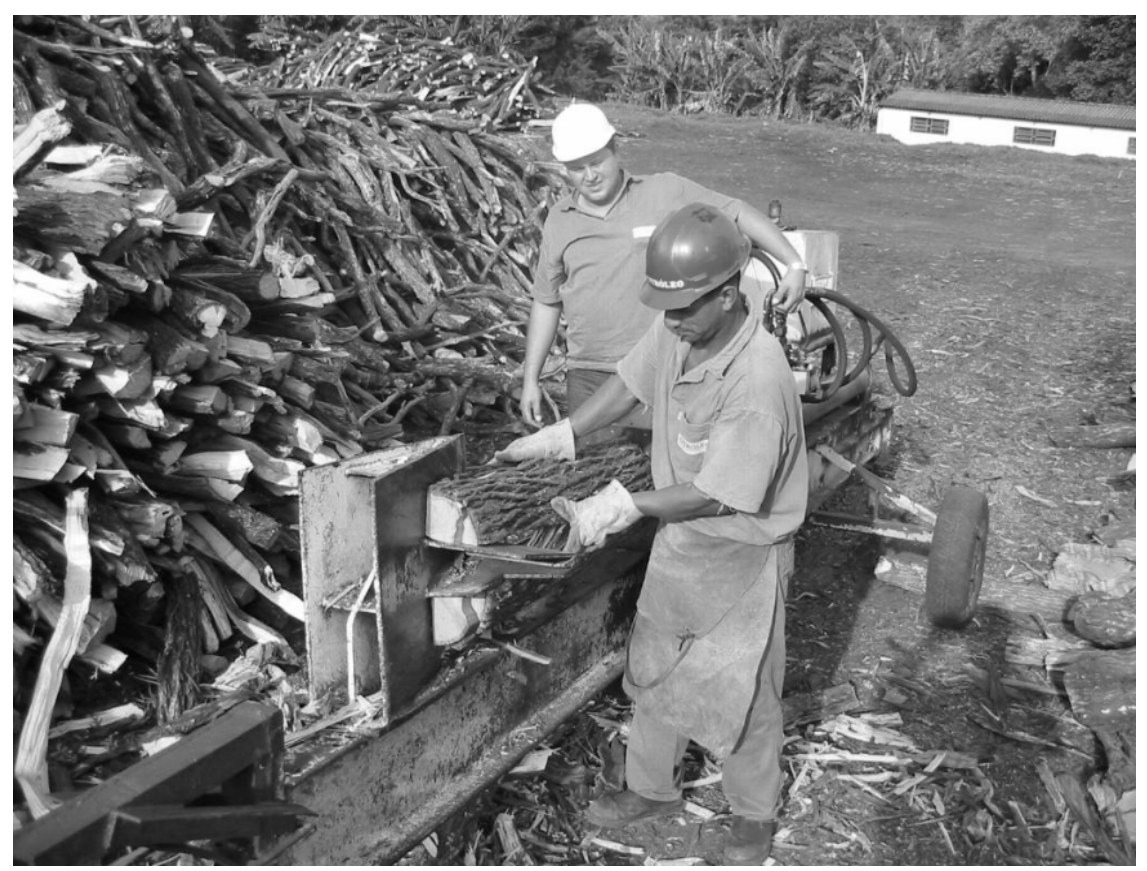

Figura 8. Madeira com diâmetro maior que $30 \mathrm{~cm}$ é seccionada.

Figure 8 . Wood with diameter greater than 30 centimeters are split. 
Transformação em cavacos

A madeira passa pelo picador para se tornar material particulado com baixa granulometria (Figuras 9 e 10), de modo a facilitar a extração do óleo essencial.

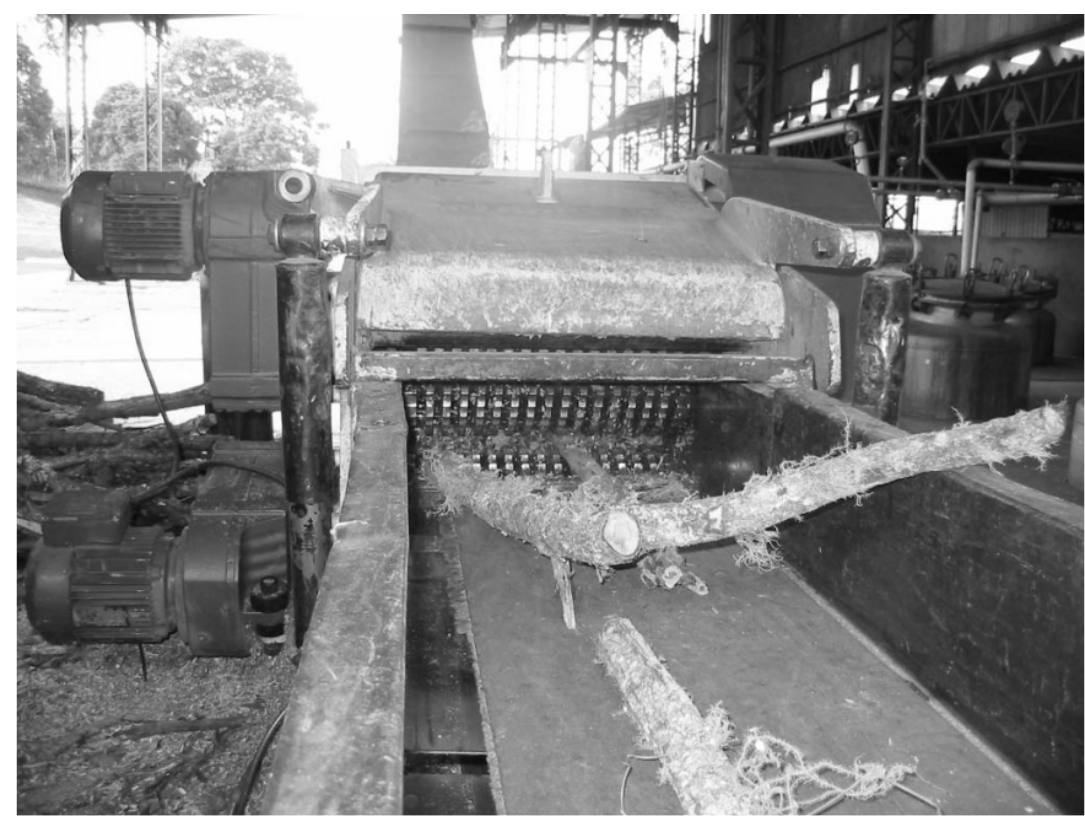

Figura 9. Picador de tambor.

Figure 9. Wood chipper.

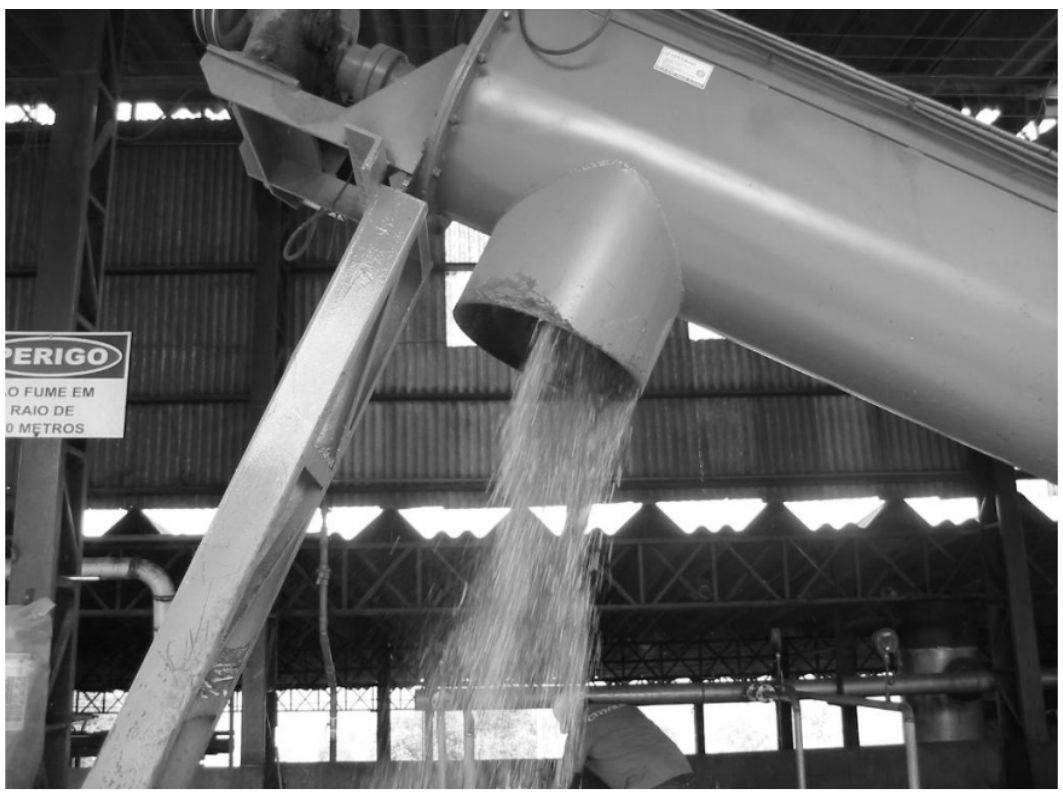

Figura 10. Madeira picada.

Figure 10. Chipped wood.

Características do material particulado

Umidade: 28,23\%; Método utilizado: secagem em estufa por 48 horas, com temperatura de $102{ }^{\circ} \mathrm{C}\left( \pm 3{ }^{\circ} \mathrm{C}\right)$.

Densidade Aparente: $315 \mathrm{~kg} / \mathrm{m}^{3}$; Método: ABNT NBR 6922 out 1981.

Granulometria - Método: ABNT NBR 7402 jul de 1982, apresentado na figura 11. 


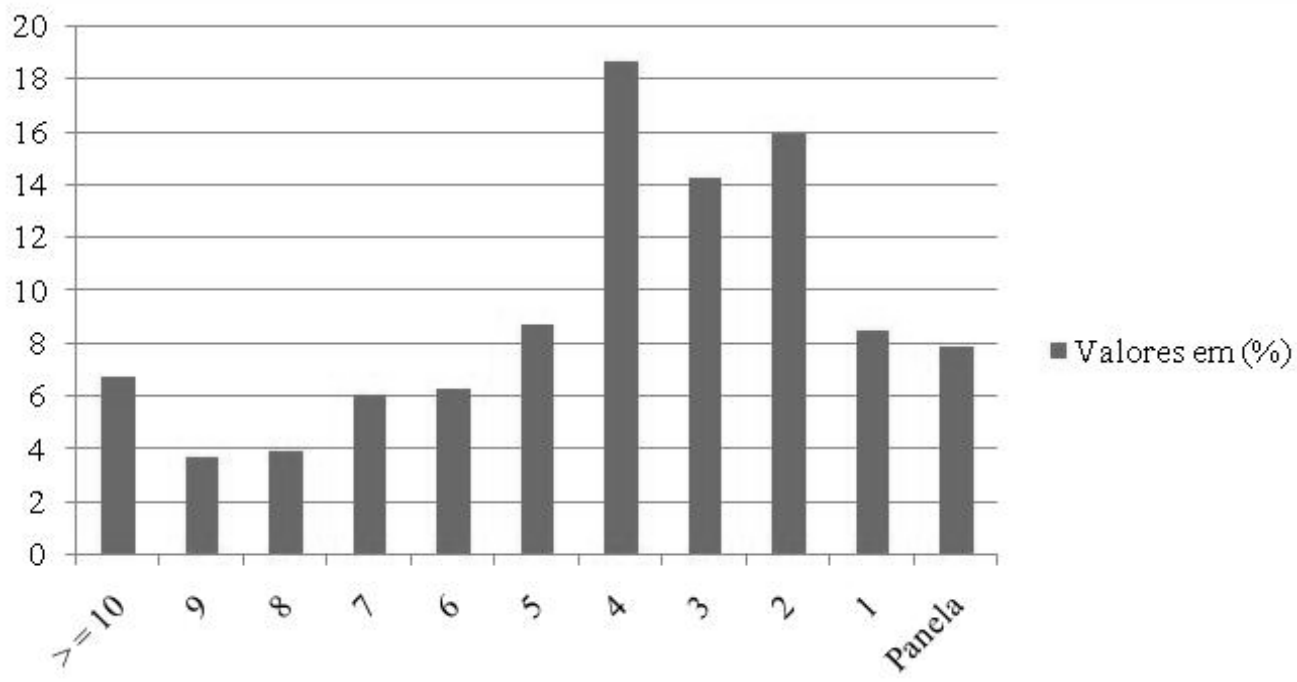

Figura 11. Gráfico apresentando a granulometria encontrada na amostra.

Figure 11. Graphic showing the grain size of the samples.

Poder calorífico do material

O poder calorífico foi analisado com o objetivo de compará-lo com outras fontes de energia.

Para tanto, foi utilizada a bomba calorimétrica de Berthelot-Mahler.

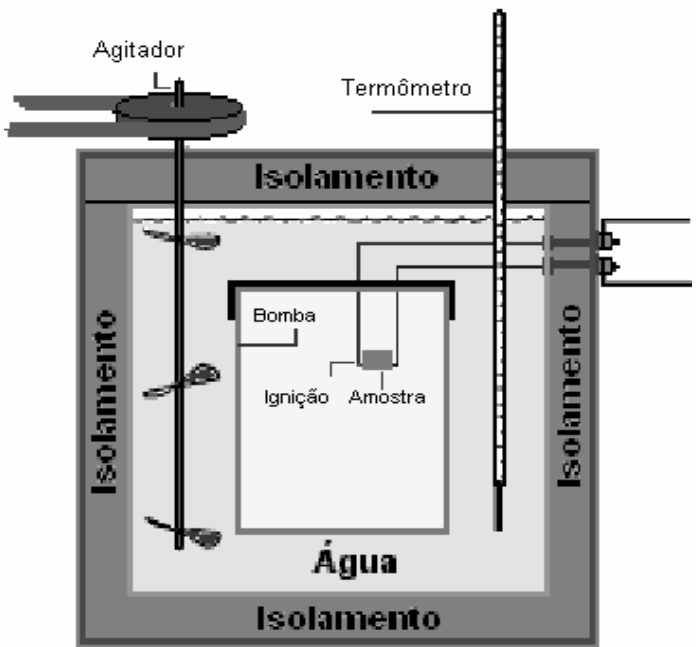

Figura 12. Bomba calorimétrica de Berthelot-Mahler.

Figure 12. Berthelot-Mahler Calorimetric Bomb.

A bomba calorimétrica utilizada é um equipamento com isolamento térmico e reservatório dotado de agitador interno, com capacidade para $2000 \mathrm{~g}$ de água destilada. A amostra de madeira é prensada, obtendo-se uma pastilha que é colocada em um cadinho enrolada em um fio de níquel/cromo com comprimento conhecido e acondicionado no interior da bomba. A bomba então é pressurizada com 25 atm de oxigênio puro, e as extremidades do fio são ligadas à energia elétrica. Após a ignição, verificase o aumento da temperatura através de um termômetro que está imerso na água.

Demonstração dos resultados

Na tabela 1 são mostrados os valores de PCS e PCI encontrados em amostras obtidas após o processo de extração do óleo essencial. 
Condições das amostras.

Amostra 01 - Grossa e úmida.

Amostra 02 - Grossa e seca.

Amostra 03 - Moída e seca.

Amostra 04 - Moída e seca.

Tabela 1. Resultado do poder calorífico com diversas condições das amostras.

Table 1. Calorific Power results, with several samples conditions.

\begin{tabular}{lcc}
\hline Amostras & PCS (cal) & PCI (cal) \\
\hline Grossa úmida & 6172,51 & 5821,51 \\
Grossa seca & 8751,73 & 8400,73 \\
Moída seca & 9109,88 & 8758,88 \\
Moída seca & 9143,06 & 8821,00 \\
\hline
\end{tabular}

Cabe ressaltar que os valores obtidos foram altos, cerca de $30 \%$ acima do esperado para a maioria das espécies de madeira do cerrado. Em função disso, os testes foram repetidos por três vezes no laboratório da UNESP de Botucatu, confirmando-se os resultados.

Entretanto, devido à pouca representatividade estatística do experimento, só podemos deduzir a partir desses dados que o material ainda apresenta bom potencial para utilização em caldeira, mantendo seu poder calorífico mesmo após o processo extrativo. Seriam necessários ensaios complementares para afirmar-se de maneira categórica os valores de PCI e PCS para a madeira de candeia.

\section{Retirada dos extrativos}

Nessa etapa separam-se os extrativos da madeira de seus demais componentes lignocelulósicos. Uma informação difícil de ser determinada e que foi omitida neste estudo é o rendimento do óleo essencial de candeia em relação ao volume de madeira, uma vez que ele é muito variável em função do diâmetro das árvores e da região da planta da qual se obtêm os cavacos, podendo levar a apresentar valores imprecisos. Também se ressalta que o processo de destilação não utiliza nenhum tipo de solvente, mantendo o mínimo impacto ambiental dos resíduos gerados.

\section{Carregamento das dornas}

Após passar pelo picador, a madeira picada em cavacos sem controle de granulometria é colocada nas dornas (recipientes metálicos para extração), conforme figuras 13 e 14 .

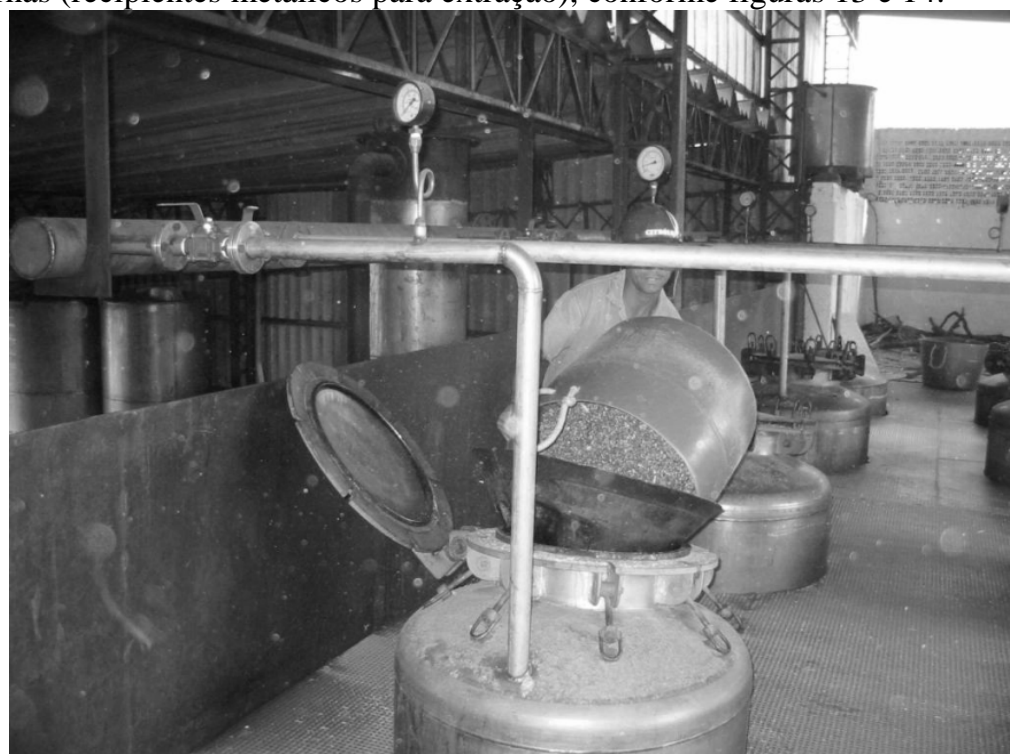

Figura 13. Dorna sendo carregada com a madeira em cavaco.

Figure 13. Pressure vase being loaded with wood flakes. 


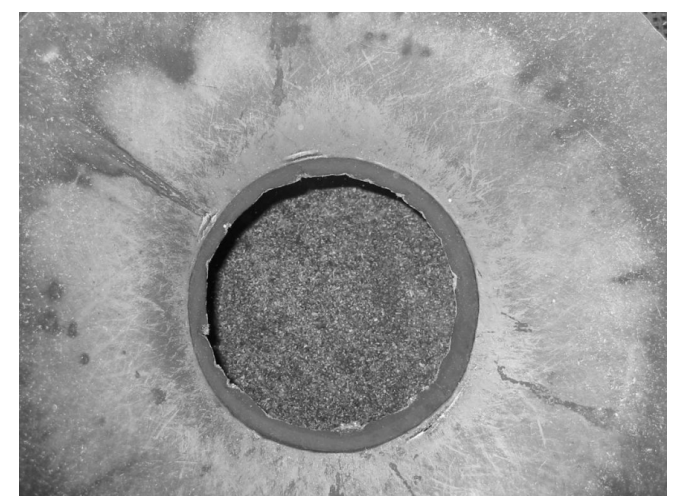

Figura 14. Dorna completamente carregada com a madeira em cavaco. Figure 14. Pressure vase completely load with wood flakes.

Em seguida, as dornas são fechadas e aplica-se vapor d'água à pressão de 0,8 até $1,8 \mathrm{kgf} / \mathrm{cm}^{2}$, dependendo do diâmetro das partículas de madeira (quanto maior o diâmetro das partículas, mais óleo essencial contido, portanto, maior pressão), por um período de 8 horas.

Durante esse período, o vapor entra através de uma tubulação, pela parte inferior da dorna (Figura 15), atravessa toda a madeira e, por arraste, retira as partículas de óleo essencial que se encontram nos cavacos. O vapor com as partículas de óleo essencial é coletado por uma tubulação na parte superior da dorna, que conduz essa mistura para o condensador (Figura 15).

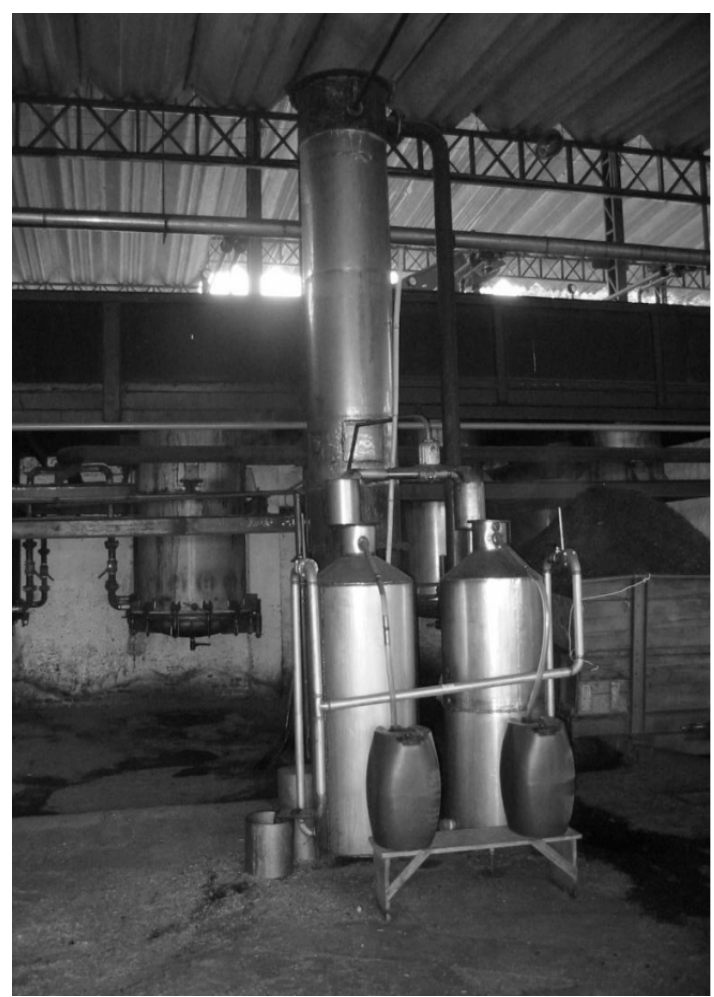

Figura 15. No fundo à esquerda, vê-se a parte inferior da dorna, na qual se percebe a tampa inferior e a tubulação de entrada de vapor. Em primeiro plano aparece o condensador.

Figure 15. In the background, on the left, the pressure vase bottom is presented. Revealing the cover and the steam pipes. The condenser is located on the front.

Após processamento de 8 horas, as dornas são descarregadas pela parte inferior (Figura 17). 


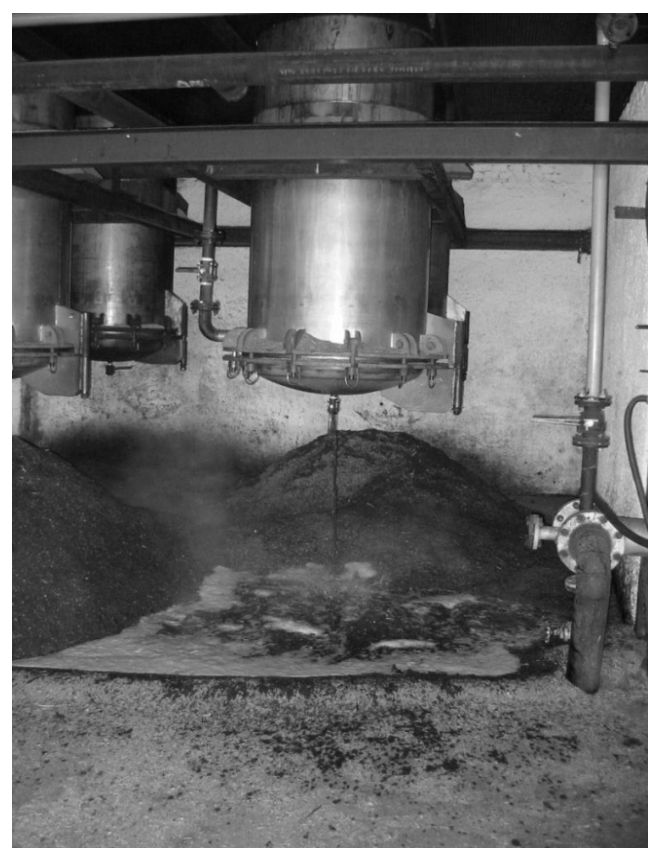

Figura 16. Retirada completa do vapor e líquido da dorna.

Figure 16. Complete steam and liquid removal from the pressure vase.

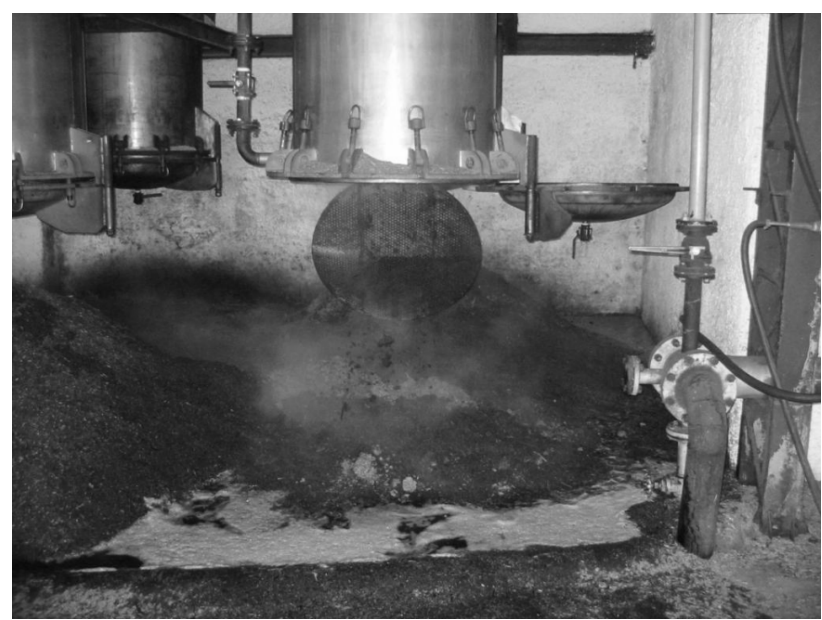

Figura 17. Dorna descarregada e totalmente aberta na parte inferior, pronta para ser fechada e carregada novamente.

Figure 17. Opened and completely unload pressure vase, ready to be used again.

Em seguida, essa carga de cavaco umedecida pelo vapor e com baixo teor de óleo essencial é transportada para perto da caldeira, à qual servirá de combustível (Figura 18).

$\mathrm{Na}$ etapa seguinte, o óleo essencial de candeia é neutralizado com uma solução alcalina e enviado para um destilador (Figura 19). O produto é destilado a uma pressão negativa (vácuo) por um período de 40 horas, para ser transformado em alfabisabolol, o produto principal. Desse processo, $95 \%$ são transformados em alfabisabolol, que é acondicionado em bombas plásticas de 20 litros, as quais, por sua vez, são acondicionadas em caixas de madeira compensada, para serem exportadas para o mercado consumidor, principalmente a Alemanha, onde é utilizado na indústria farmacêutica e cosmética (Figura 20). Os 5\% restantes, que são denominados de resina, são estocados em tambores de latão, aguardando uma destinação final, que poderá ser substituir o CCC (cromo, cianeto e cobre) no processo de tratamento de madeira em geral. 


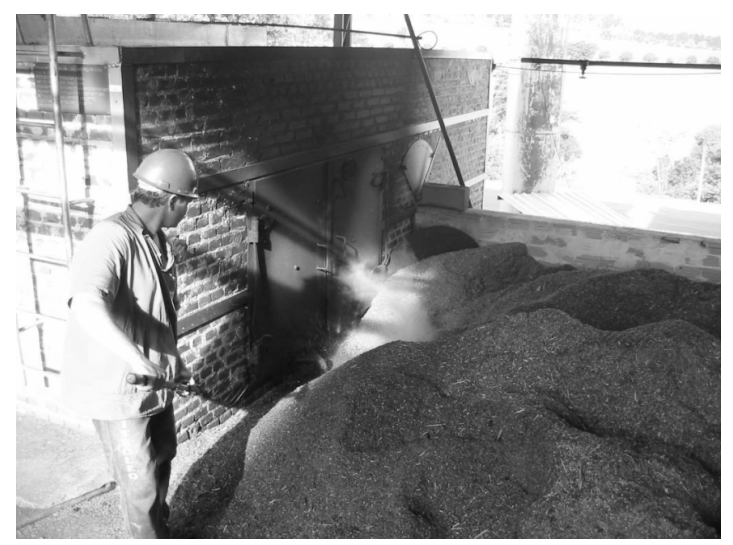

Figura 18. Alimentação da caldeira.

Figure 18. Steam-boiler feed.

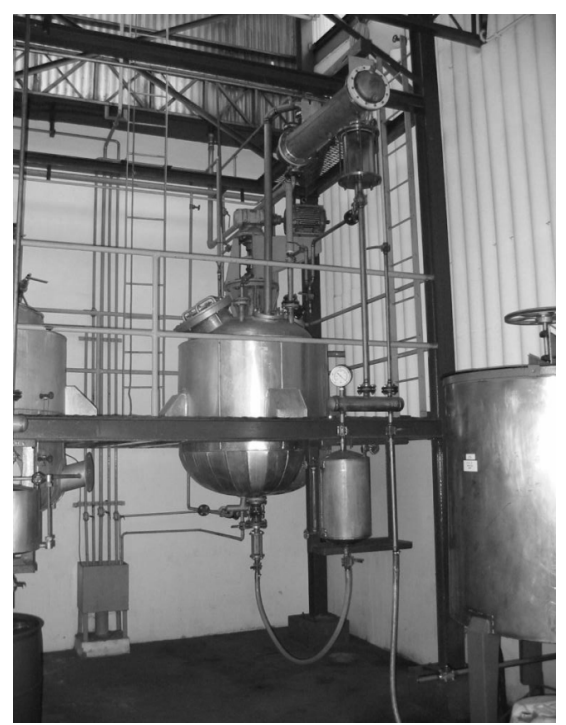

Figura 19. Destilador de óleo de candeia. O alfabisabolol é o produto final. Figure19. Candeia oil distiller. The final product is Alpha-Bisabolol.

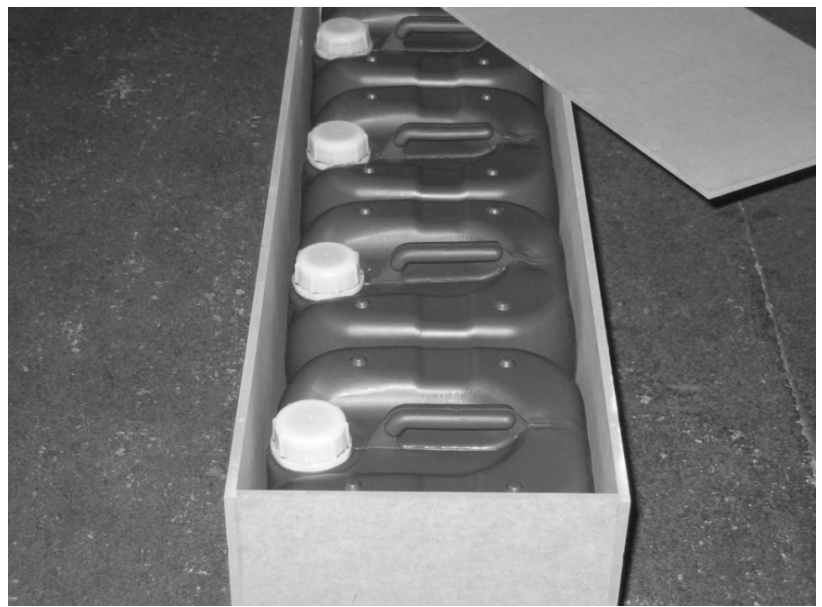

Figura 20. Óleo alfabisabolol pronto para ser comercializado.

Figure 20. Alpha-bisabolol ready for sale. 


\section{CONSIDERAÇÕES FINAIS}

O sistema de porta-sementes com regeneração natural aliado ao processo de extração de óleo essencial apresentado é simples, podendo ser viabilizado com uma infraestrutura mínima, de custo relativamente baixo e de tecnologia disponível, apresentando potencial para ser reproduzido em outras regiões do país com características similares, sendo ainda possível fonte de geração de emprego e renda para populações carentes. Além disso, é uma aplicação mais nobre da matéria-prima que possivelmente seria utilizada para a produção de carvão.

A técnica de manejo sustentado, portanto, tem potencial para preservar a flora e a fauna original, mantendo-se uma atividade econômica viável. Através dessa atividade, espera-se diminuir a agressão ao meio ambiente, com queimadas e desmatamento indiscriminado, que usualmente é praticada na região.

O manejo sustentado deve ser auxiliado por suporte de pessoal técnico especializado, e isso é viabilizado nesse caso, tendo como retaguarda a Universidade Federal de Lavras (MG).

No corte, são utilizadas apenas ferramentas convencionais, com mínimo impacto, como facão, enxada, foice, gadanho e somente algumas vezes motosserra.

O transporte dentro das florestas até um local a que se tenha acesso com veículos maiores (caminhões "toco" e carretas), é feito em lombo de burros, minimizando efeitos sobre as demais espécies na retirada.

É possível gerar renda, envolvendo a população local, onde outros tipos de culturas são desfavoráveis, por causa da baixa fertilidade do solo e do terreno pedregoso.

\section{CONCLUSÕES}

No processo de extração, não existem sobras de materiais, nem resíduos que possam agredir o meio ambiente.

A madeira residual, de onde é extraído o óleo essencial, é utilizada como fonte de energia na geração de vapor pelas caldeiras, fechando o ciclo de carbono.

Finalmente, é importante ressaltar que, além do aspecto sustentável, esse é um produto de alto valor agregado, que pode ser gerador de divisas para o país, por intermédio de sua exportação.

\section{REFERÊNCIAS}

ARAÚJO, L. C. Vanillosmopsis erythropappa (DC) Sch. Bip: sua exploração florestal. Rio de Janeiro: Escola Nacional de Agronomia, 1944. 58 p.

CARVALHO, P. E. R. Espécies florestais brasileiras: recomendações silviculturais, potencialidade e uso da madeira. Brasília: EMBRAPA-CNPF, 1994. 640 p.

CETEC - CENTRO TECNOLÓGICO DE MINAS GERAIS. Ecofisiologia da candeia. Belo Horizonte, set. 1994. 104 p.

Centro Tecnológico de Minas Gerais/FNMA: Memória Técnica. Belo Horizonte, set. de 1994. não paginado.

CHAVES, M. M. F.; RAMALHO, R. S. Estudos morfológicos em sementes, plântulas e mudas de duas espécies arbóreas pioneiras da família Asteraceae (Vanillosmopsis erythropappa Schult. Bip. e Vernonia discolor (Spreng-Kess). Revista Árvore, Viçosa, MG, v. 20, n. 1, p. 1-7, jan./mar. 1996.

CORREA, M. P. Dicionário de plantas úteis do Brasil. Rio de Janeiro: Ministério da Agricultura, 1931. v. 1, p. 431-433.

FENNER, P. Métodos de cronometragem e a obtenção de rendimentos. Notas de aula, UNESP Botucatu-SP.

MATTHEWS, J. D. Silvicultural Systems. Oxford: Oxford University Press, 1994. 284 p. 
PEDRALLI, G.; TEIXEIRA, M. C. B.; NUNES, Y. R. Estudos sinecológicos sobre a candeia (Vanillosmopsis erythropappa Schult. BIP) na estação ecológica do Tripui, Ouro Preto, MG. Revista Árvore, Viçosa, MG, v. 21, n. 2, p. 301-306, 1997.

SCOLFORO, J. R. S. Manejo Florestal. Lavras: UFLA/FAEPE, 1998. 438 p.

TEIXEIRA, M. C. B.; NUNES, Y. R. F.; MAIA, K. M. P.; RIBEIRO, R. N. Influência da luz na germinação de sementes de candeia (Vanillosmopsis erythropappa Shuh. Bip.). In: ENCONTRO REGIONAL DE BOTÂNICA, 28., 1996, Belo Horizonte. Anais... Belo Horizonte: SBB: Pontifícia Universidade Católica de Minas Gerais, 1996. p. 35-41. 